\title{
Medical Laboratory Equipment business buying decision-making: The case of Kenyan Public Hospitals
}

\author{
Nnamdi O. Madichie, PhD* \\ Bloomsbury Institute, London, United Kingdom \\ Email: nnamdi.madichie@bil.ac.uk \\ Coal City University, Enugu, Nigeria \\ Email: nnamdi.madichie@ccu.edu.ng \\ ORCID: http://orcid.org/0000-0001-8400-5527 \\ Josephat SUA \\ Managing Director \\ Microbiology E.A. Ltd \\ Ridgeways Brook Rd/ Off Kigwa Road \\ PO Box 1530-00200 \\ Nairobi, Kenya \\ Tel: +254 771990 990, +254 728563 440, +254738130773 \\ Email: sua@microbiology.co.ke \\ URL: www.microbiology.co.ke
}

\begin{abstract}
The aim of this study was to establish who makes procurement decisions, what resources are used while researching the business buying decision-making process in the procurement of capital medical laboratory equipment (CMLE) in public hospitals. Participants for the study were selected using purposive sampling with a view to providing insights into the explored issues. The target respondents were medical superintendents, medical laboratory technologists, and procurement officers in six county referral hospitals in Kenya between May to June 2018. The findings show that medical salespersons, catalogues, and referrals from colleagues were consulted when researching CMLE procurement. Factors considered important in the business decision-making included quality, continuity of reagents supply, supplier capability, equipment costs, and ease of use. Public hospitals in Kenya should adopt participatory purchasing models where more stakeholders such as buyers, lower level employees in hospital departments, and physicians, are included in the buying decisionmaking.
\end{abstract}

Keywords: Business decision-making; Capital Medical Laboratory Equipment; Procurement decisions; Public County Referral Hospitals; Kenya 


\title{
Medical Laboratory Equipment business buying decision-making: The case of Kenyan Public Hospitals
}

\begin{abstract}
The aim of this study was to establish who makes procurement decisions, what resources are used while researching the business buying decision-making process in the procurement of capital medical laboratory equipment (CMLE) in public hospitals. Participants for the study were selected using purposive sampling with a view to providing insights into the explored issues. The target respondents were medical superintendents, medical laboratory technologists, and procurement officers in six county referral hospitals in Kenya between May to June 2018. The findings show that medical salespersons, catalogues, and referrals from colleagues were consulted when researching CMLE procurement. Factors considered important in the business decision-making included quality, continuity of reagents supply, supplier capability, equipment costs, and ease of use. Public hospitals in Kenya should adopt participatory purchasing models where more stakeholders such as buyers, lower level employees in hospital departments, and physicians, are included in the buying decisionmaking.
\end{abstract}

Keywords: Business decision-making; Capital Medical Laboratory Equipment; Procurement decisions; Public County Referral Hospitals; Kenya

\section{Introduction}

Medical laboratory testing plays a very crucial role in detection, diagnosis, and treatment of diseases in patients. According to the World Health Organisation (WHO, 2011), anything between 60 to 70 percent of most important decisions on admission, discharge, and medication are based on laboratory tests. The ability to offer quality laboratory services depends on the type of equipment in use at the hospital laboratory. With the advancement of information technology, medical technology in the field of laboratory equipment has also grown. This presents a complex environment to the hospital and laboratory managers on how to choose the best medical device for their hospitals.

WHO (2011) defines a medical device as an article, instrument, apparatus or machine that is used in the prevention, diagnosis or treatment of illness or disease, or for detecting, measuring, restoring, correcting or modifying the structure or function of the body for some 
health purpose. A medical equipment is a medical device requiring calibration, maintenance, repair, user training, and decommissioning - activities usually managed by clinical engineers (WHO, 2011). In terms of cost, Juhas (2015) defines capital medical equipment as costing in a tune of US\$5000, is not a consumable or disposable, is standalone and has got a useful life of more than one year.

Understanding buyer behaviour and identifying important people who researches and makes procurement decisions in hospitals plays a role in formulating key marketing programs in any marketing organization. Bahadori et al. (2012) posit that understanding the determinants that could influence consumer purchasing decisions are critical for medical equipment manufacturing companies competing in the competitive global environment. Additionally, Lichtenberger et al. (2010) conducted a study that whose findings established that effective procurement practices lead to safe, equitable and quality health care services. The results from the analysis established that better procurement practices can help hospitals achieve rapid supply cost reductions of 20 percent or more and keep future cost escalations under control.

This study explored the question on who researches and makes procurement decisions for capital medical laboratory equipment in public hospitals in Kenya. It also sought to answer the question regarding which research tools are used while researching for procurement of medical equipment and the business buying decision-making process in the procurement of these equipment. It is envisaged that the findings of this study will assist manufacturers and distributors of medical laboratory equipment better target public hospitals with the right products and prospects, and the right people in procurement decisions across the hospitals in the country. The findings will also provide deeper insight into the person (or persons) responsible for researching and making procurement decisions for capital medical laboratory equipment in public hospitals. Collectively, these findings will be of value to public procurement policy makers and hospital administrators in informing them on the level of collaboration and efficiency in the procurement process of capital medical laboratory equipment in public hospitals. This might be useful in any future plans for reforming the procurement process in this sector in order to ensure a judicious use of funds that provides value for money for public resources. 
Overall, the aim of the study is to establish the business buying decision-making system regarding capital medical laboratory equipment purchases in Kenyan Public County Referral Hospitals. The study was guided by the following three objectives:

- To establish who researches and makes procurement decisions for capital medical laboratory equipment in public hospitals in Kenya.

- To understand which resources are used while researching for the procurement of capital laboratory equipment.

- To explore the business buying decision-making process in the procurement of capital medical laboratory equipment in public hospitals in Kenya.

\section{Literature Review}

A medical laboratory equipment is a device designed to aid in the diagnosis, treatment, prevention, rehabilitation and monitoring of medical conditions (WHO, 2011). Kirankumar \& Chauhan (2017) point out that medical laboratories are indispensable part of healthcare services, as most of the time physicians must make their crucial clinical decisions in accordance with clinical laboratory results. Kirankumar \& Chauhan (2017) further assert that medical laboratories must be able to produce precise and accurate results. According to WHO (2011), 60 to 70 percent of most important decisions on admission, discharge, and medication are based on laboratory tests. Inaccurate laboratory test results lead to under diagnosis, over diagnosis and misdiagnosis, which may impact the clinical quality and cost-effectiveness of care and patient safety (Horvath, 2013). The ability to offer quality laboratory services depend on the type of equipment the hospital laboratory procures.

Public procurement is the process that government entities go through to acquire or purchase goods and services (Public Procurement Oversight Authority, 2013). Government hospitals pre-select individuals and firms that have the ability to provide the essential equipment's at a reasonable price and within pre-determined timelines. The efficiency of a country's procurement system plays a significant role in provision of quality health services to her citizens (Ramadhani, 2015). In this context, Terio (2010) notes that a well-defined procurement process is an essential part in offering quality healthcare. 


\subsection{Procurement Decisions for CMLE}

A study by Wagner (2017) in US assessed the most popular mode of purchasing of capital equipment in US healthcare institutions. The study established that Group Purchasing Organizations (GPOs) are mostly used in US and they began in the late 1880s and grew in the 1970s and 80s. The study established that currently, there are over six hundred GPOs in the United States, with the two largest being Premier and Novation. The study revealed that 72 percent of hospital purchases are made from Group Purchasing Organizations. Additionally, the study established that top seven GPOs control 85 percent of market share in US. An earlier research by Muken and Cherney (2013) established that most of the hospitals using GPOs use more than two each claiming to offer lower purchasing costs. The study further noted that GPOs worked on a large scale by aggregating their members' purchasing demands to make favourable contracts with manufacturers. A GPO works as an intermediary, charging buyers and manufacturers for using its services, and offering rebates and discounts to hospitals. Despite the high use of GPOs, there were strengths and weaknesses to negotiating a contract with one. For instance, GPOs operate under regimes related to volume commitment and can negotiate with the seller. The rebates that a member hospital receives are tied to the percent of total purchases that hospital makes through the GPO, rather than the quantity or dollar volume of purchases. One disadvantage for using by GPOs was that they did not encourage innovation.

In a 2013 collaborative effort with HIMSS Analytics, Google conducted a study to get a better understanding of the decision-making influences in the purchase of medical devices. That study entitled "The doctor will see you now: How hospital administrators make purchase decisions," ${ }^{1}$ involved 749 hospital decision makers with a focus on four product areas - namely Imaging Equipment (MRI, Ultrasound etc.); Electronic Health Records; implants and medical devices; and surgical equipment. The results from the study established that there was a variety of stakeholders and influencers (i.e., hospital administrators, medical directors, physicians, directors of surgical services, directors of purchasing, and procurement officers) involved in the procurement of capital medical equipment.

\footnotetext{
${ }^{1}$ Google (2013) The doctor will see you now: How hospital administrators make purchase decisions, Think With Google, October 2013, https://www.thinkwithgoogle.com/intl/en-gb/future-of-marketing/machinelearning/how-hospital-administrators-make-purchase-decisions/
} 
In a 2013 Honours Thesis Alana investigate the effectiveness of participatory approaches to purchasing decisions within the healthcare system. That study evaluated avenues for expanding the purchasing model of a large hospital in the Northeast of Connecticut (USA), based upon interactive and participatory approaches (Dorris, 2013). The study revealed the prevalence of Group Purchasing Organisations (GPOs) in most purchasing decisions. It also surmised that such GPOs proved more effective - even less innovative - than when undertaken through manufacturers directly. One implication that emerged from that study was that most hospitals were limited as a result of the amount of end-user participation in the purchasing decision process. This meant that there was a need to ramp up participatory involvement in the purchasing process - weaving in all stakeholders (i.e., buyers, employees in hospital departments, physicians, and patients).

\subsection{Researching for the procurement of CMLE}

The study by HIMSS Analytics (2013) investigated the resources used by hospitals to research on capital equipment procurement. The study sought to understand the digital resources that influence hospital administrators during their purchase journey. Most of the buyers indicated that there is not the funding there used to be to go to conferences and trade shows, and they are time consuming as well. Study findings revealed that 77 percent of the buyers have direct sales contact with vendor, 70 percent utilize a Group Purchasing Organization (GPO), 54 percent utilized colleague recommendation, 51 percent utilized online resources while 34 percent utilized internal resources from previous procurement. Moreover, only 28 percent utilised professional societies or conferences. The study further noted that digital tools are utilised and influence decision making throughout a buyer's decision journey. Most of the used online resources included online search engines, tablets, mobile phones, and online video showcases of product features and functionalities. The study further established that buyers used search engines to gather information on products and vendors. Specifically, 94 percent used online search engines to research product features, 90 percent to identify vendors while 82 percent used online search engines to compare products.

Bahadori et al. (2012) argue that understanding the determinants that could influence consumer purchasing decisions are critical for companies especially that are competing in a global environment. Effective procurement practices lead to safe equitable and quality health care services. The purchasing process starts with recognizing a need which then leads to the next phase of researching on alternatives that can satisfy that need. Understanding buyer 
behaviour and establishing the resources they use to identify, compare, and learn about existing capital medical equipment critical for the manufacturers. With such information, manufacturers can ensure that information about their capital medical equipment is available in the mediums and form that buyers utilise.

\subsection{Decision-making process in CMLE procurement}

Prior research have acknowledged the need to address increasing healthcare procurement costs and offered specific approaches to addressing this problem. On the one hand there have been advocates (Google, 2013; Dorris, 2013; Wagner, 2017) for participative process where various stakeholders including product users, physicians, accounting, and procurement officers have their input into the procurement decisions for capital medical equipment. The Google study, for example, reported that while $42 \%$ of decision makers initiate purchasing decisions because of user requests, $71 \%$ percent of decision makers in the procurement of initiated purchasing decisions at the point of replacement of "used or out-dated" technology. The study also revealed that about $60 \%$ of decision-makers sought to improve clinical outcomes when deciding to purchase while about $50 \%$ opt for lower costs as a deciding factor. The study also revealed that decision-making tended to vary depending on whether it was electronic health records and imaging equipment (which typically have longer sales cycles) vis-à-vis surgical and medical devices.

On the other hand, however, Muken \& Cherney (2013) seem to suggest the need for a more structured process that places both quality and cost above participation as being more of a priority. This study, however, takes a hybrid approach by proposing that an integrative posture should be considered that takes on-board a more comprehensive view would be more appropriate for such healthcare procurement practices. This integrative view considers the need for a holistic framework for efficient procurement of CMLE that a better suited to developing world contexts - including Kenya, which are more exposed to information asymmetry challenges.

\section{Methodology}

The study employed convergent parallel mixed methods design as described by Hui Bian (2013). He defines this kind of design as as a 'method which focuses on collecting, analyzing, and mixing both quantitative and qualitative data in a single study or series of studies'. Its 
central premise is that the use of quantitative and qualitative approaches, in combination, provides a better understanding of research problems than either approach alone. The quantitative data collection involved having structured questions in the questionnaire seeking information on persons with the responsibility for researching and making procurement decisions, resources used while researching and business buying decisionmaking process for the procurement of CMLE. Qualitative data was collected through open questions in the questionnaires that sought information on resources the research participants would recommend for the county referral hospital that are not currently fully utilised by the hospital in researching for the procurement of CMLE. Additionally, qualitative data was collected in regard to recommendations on improvements in business buying decisionmaking process in the procurement of CMLE.

The study relied on primary data, which was collected using a semi-structured questionnaire. The target respondents were medical superintendents, laboratory technologists and procurement officers in six county referral hospitals in Kenya. The counties were selected purposively to represent a wide range of aspects including income levels and health outcomes. They included two predominantly rural counties, two predominantly urban counties and two predominantly low income and remote counties with variant health issues. The study respondents were selected using purposive sampling so as to get respondents who would provide important information for the study.

Eighteen questionnaires were distributed to the hospitals and administered to the medical superintendents, medical laboratory Technologists, and procurement officer of each of the six selected hospitals. The administration was conducted in the months of May and June 2018. Out of the 18 questionnaires distributed, 12 were returned after being filled by the respondents. This makes a response rate of 67 percent. The filled questionnaires were found to be fit for analysis. Structured items in the questionnaires were analysed and using quantitative techniques, which included frequencies, percentages and means. The qualitative data collected through the open items in the questionnaire was analysed using thematic summary analysis. This entails pinpointing, examining, and recording patterns within the collected data (Babbie, 2011).

This study applied both exploratory and inductive kind of study. Saunders, Lewis, and Thornhill (2012) posit that an inductive research approach alternatively starts with research 
objectives and aims or research questions that the researcher seeks to achieve in the study. This is then followed by the process of data collection that enables the researcher to establish relationships and patterns in the data and variables of study. This can then be used to build a theory. The current study involved developing of research aims and objectives, collecting both qualitative and quantitative data through a semi-structured questionnaire and analysing the data to establish the patterns in the data, the inductive approach was hence justified for this study.

The research design as noted by Coolican (2014) refers to the general approach that the researcher applies to assimilate the diverse aspects of the research in a logical and coherent way so that the research problem and objectives can be effectively addressed. Creswell and Creswell (2018) indicated that research design determines how data will be collected, the measurements to be used, and how the collected data will be analysed and interpreted. This study adopted a descriptive research design as it assisted in providing information to satisfy the research aims and objectives (Coolican, 2014; Creswell, 2018). In addition, Babbie (2011) postulates that descriptive research is applied to gain information regarding the current status of a certain phenomenon that is under investigation. In the study, this design enabled to describe the people responsible for researching and making procurement decisions for capital medical laboratory equipment in public hospitals in Kenya. Moreover, the study established the resources deployed while researching for the procurement of CMLE and the business buying decision-making processes applied.

\subsection{The Kenyan Healthcare System}

The Kenyan healthcare system is divided into three subsystems depending on the agency, which owns them (Kenya Health Sector Survey, 2016). These are public hospitals (owed by the government), commercial private hospitals (privately owned by medical practitioners) and faith-based hospitals (owned by religious entities). In total, there are over five thousand health facilities in Kenya. The public sector accounts for 48 percent of all the health facilities, while 35 percent are privately owned, and 15 percent are owned by faith based organizations (Gachie, 2013). The healthcare expenditure in 2016 was approximately USD 3.9 billion, which constituted six percent of the country's GDP (Republic of Kenya, 2017). The public sector took 61 percent of the funding while the rest was shared by the private and Faith based healthcare facilities. 
Kenya has a long-term development plan named 'Vision 2030', which aims to transform the country into a middle-income economy by the year 2030 (Health Sector Opportunities in Kenya, 2017). Healthcare is one of the key pillars of Vision 2030. The aim is to maintain a healthy workforce by providing equitable, affordable, and quality healthcare to the entire country. The public sector dominates the Kenya's healthcare sector, but the quality of the healthcare services provided by government varies from county to county and is still wanting. Kenya's investment in the health care sector over the past five years (2012-2016) has averaged 2.8 percent of the GDP, which compares poorly with that of developed countries such as US (10.1\%) and UK (12.5\%) (Piabuo \& Tieguhong, 2017). The low investment in health sector implies that efficiency and value for money should be key factors in procurement of CMLE in public healthcare facilities in Kenya.

In 2010, Kenya adopted a new constitution, which created a devolved system of government with 47 county governments. The 47 county governments have relatively high degree of autonomy when it comes to budget allocations including healthcare. According to the Kenyan constitution, county governments are funded by the national government as part of fiscal devolution (CoK, 2015).

Healthcare financing is usually undertaken by the government-operated National Hospital Insurance Fund (NHIF), private insurance schemes, employer medical schemes and out of the pocket user fees. For the last few years, Kenya has been undergoing healthcare reforms. Even though the budgetary allocations have been increasing year after year, the rise has not been commensurate to the rising costs of medical care. Hospital administrators are faced with diminishing budgets, the need to keep the costs low while at the same time trying to maintain the quality of healthcare services. CME Corp (2015) suggests that faced with these challenges hospital managers need to look for cost-efficient ways to invest the limited capital (see Juhas, 2015). Ondigi \& Muturi (2015) argue that procurement excellence can help in enhancing quality of healthcare services while lowering costs.

\section{Findings}

This study sought to establish the business buying decision-making processes involved in the purchase of capital medical laboratory equipment across Public County Referral Hospitals in Kenya. In this section, the main findings are reported - from responsibility for undertaking 
initial research for suitable vendors, through resources used to making informed decisions, to the actual decision-making.

\subsection{Responsibility for Researching and Making Procurement Decisions for CMLE}

The first objective of the study was to establish who researches and makes procurement decisions for capital medical laboratory equipment in public hospitals in Kenya. Study participants were asked to indicate how often the listed members of the hospital were involved in researching for capital medical laboratory equipment. The rating used was on a three-point scale (1 - Never, 2 - Occasionally, 3 - Every time). Percentages were calculated, and the results are presented in Table 1.

Table 1: Member involvement in researching on CMLE prior to Procurement.

\begin{tabular}{|l|l|l|l|}
\hline Member & $\begin{array}{l}\text { Never } \\
(\%)\end{array}$ & $\begin{array}{l}\text { Occasionally } \\
(\%)\end{array}$ & $\begin{array}{l}\text { Always } \\
(\%)\end{array}$ \\
\hline Medical superintendent / CEO & 17 & 50 & 33 \\
\hline Medical consultants- physicians/surgeons & 67 & 25 & 8 \\
\hline Procurement officer & 8 & 42 & 50 \\
\hline Chief medical laboratory technologist & 8 & 0 & 92 \\
\hline Chief financial officer / Accountant & 42 & 25 & 33 \\
\hline Other & 0 & 60 & 40 \\
\hline
\end{tabular}

Findings presented in Table 1 show that 92 percent of the respondents indicated that chief medical laboratory technologists were involved in researching every time. Moreover, 50 percent indicated that procurement officers were involved every time while 40 percent indicated that others who had not been listed were involved every time. These 'others' included radiology directors, directors of imaging and medical directors. The finding also indicated that 67 percent of the respondents indicated that medical consultants were never involved with 42 percent indicating that chief finance officers were never involved. These findings imply that the most involved hospital member in researching on capital medical laboratory equipment before procurement were chief medical laboratory technologists and procurement officers. The study also investigated the hospital members involved in making procurement decisions for capital medical laboratory equipment. The scale used was 1 Never, 2 - Occasionally, and 3 - Every time (see Table 2). Results presented in Table 2 show 
that all the respondents (100\%) indicated that procurement officers were involved in making procurement decisions every time, $75 \%$ indicated that chief medical laboratory technologists were involved every time a purchase decision has to be made.

Table 2: Members involved in making procurement decisions for CMLE

\begin{tabular}{|l|l|l|l|}
\hline Member & Never (\%) & $\begin{array}{l}\text { Occasionally } \\
(\%)\end{array}$ & $\begin{array}{l}\text { Always } \\
(\%)\end{array}$ \\
\hline Medical superintendent / CEO & 0 & 50 & 50 \\
\hline Medical consultants- physicians/surgeons & 75 & 25 & 0 \\
\hline Procurement officer & 0 & 0 & 100 \\
\hline Chief medical laboratory technologist & 25 & 0 & 75 \\
\hline Chief financial officer / Accountant & 17 & 33 & 50 \\
\hline Other & 0 & 50 & 50 \\
\hline
\end{tabular}

These findings indicate that procurement officers, and chief medical laboratory technologists, were mostly involved in making procurement decisions for capital medical laboratory equipment in the county referral hospitals in Kenya. Medical consultants (physicians and surgeons) were rarely involved. The findings disagree with the results by HIMSS Analytics (2013) which indicated that physicians were key influencers. When respondents were asked to indicate the three mostly involved in making procurement decisions for capital medical laboratory equipment, the members mostly mentioned were chief medical laboratory technologists, procurement officers, and financial officers.

\subsection{Resources used for procurement research of CMLE}

The second objective of the study was to understand which resources are used while researching for the procurement of CMLE. Respondents were required to indicate the extent of use of the different resources in researching for the procurement of CMLE. Findings in Table 3 reveal that 75 percent of the respondents indicate that medical or sales representatives were used every time in researching for the procurement of CMLE while 67 percent indicate that medical literature, and catalogues were used every time while 58 percent indicated that referrals were used all the time. Ninety-two percent indicated that conferences and seminars were used occasionally, while 82 percent indicated that exhibitions were used occasionally. 
Other resources that were occasionally used included CME (58 percent) and electronic sources (55 percent). These findings indicated that resources that were mostly used to research CMLE during procurement included medical or sales representatives, medical literature/ catalogues and referrals by consultants or colleagues.

Table 3: Resources used while researching for the procurement of CMLE

\begin{tabular}{|l|c|c|c|}
\hline Resources & Never (\%) & $\begin{array}{l}\text { Occasionally } \\
(\%)\end{array}$ & $\begin{array}{l}\text { Always } \\
(\%)\end{array}$ \\
\hline Exhibitions & 9 & 82 & 9 \\
\hline Conferences / Seminars & 0 & 92 & 8 \\
\hline CME (continuing medical education) & 42 & 58 & 0 \\
\hline $\begin{array}{l}\text { Electronic sources - internet-mobile } \\
\text { phone / tablet / laptops }\end{array}$ & 18 & 55 & 27 \\
\hline Medical/sales representatives & 0 & 25 & 75 \\
\hline Medical literature / Catalogues & 0 & 33 & 58 \\
\hline Referrals by consultants or colleagues & 0 & 42 & \\
\hline
\end{tabular}

These results support the findings by HIMSS Analytics (2013) which revealed that 77 percent of the buyers had direct sales contact with vendor, 54 percent utilized colleague recommendation, 51 percent utilized online resources while 28 percent utilized professional societies or conferences. However, the study by HIMSS Analytics (2013) indicated that 70 percent utilized a GPO, which was not utilized by the county referral hospitals that were studied. Further, a higher number utilized electronic resources in the HIMSS Analytics (2013) that was the case in this study.

\subsection{Business Buying Decision-Making Process for CMLE Procurement}

The third objective of the study was to explore the business buying decision-making process in the procurement of capital medical laboratory equipment in public hospitals in Kenya. The study enquired the factors considered important when making the decision to procure CMLE. Results in Table 4 reveal that factors that were considered extremely important by the respondents when making the decision to procure CMLE were quality (100\%), continuity of reagents supply (100\%), supplier capability (92\%), cost of the equipment consumables $(92 \%)$, ease of use $(83 \%)$ and after sales service and spare parts availability (83\%). 
Other extremely important factors included brand of the equipment (75\%) and purchase price of the equipment (67\%). These results support the findings by Wagner (2017) that in making procurement decisions for capital medical equipment, the major considerations included quality, cost of the equipment, ease of use by the hospital staff, make and brand of the equipment, capability of the manufacturer to provide the equipment and continuing support for the equipment.

Table 4: Factors considered important when making the decision to procure CMLE

\begin{tabular}{|l|c|c|c|}
\hline Factor & $\begin{array}{l}\text { Not at all } \\
\text { important } \\
(\%)\end{array}$ & $\begin{array}{l}\text { Moderately } \\
\text { important } \\
(\%)\end{array}$ & $\begin{array}{l}\text { Extremely } \\
\text { important } \\
(\%)\end{array}$ \\
\hline Manufacturer \& Country of Origin & 0 & 50 & 42 \\
\hline Brand of the Equipment & 0 & 0 & 75 \\
\hline Quality & 0 & 17 & 83 \\
\hline Usability (ease to use) & 0 & 33 & 67 \\
\hline Purchase price (Cost of the equipment) & 0 & 8 & 92 \\
\hline Cost of the equipment consumables & 0 & 0 & 100 \\
\hline Continuity of reagents supply & 0 & 17 & 83 \\
\hline After sales service \& Spare parts availability & 8 & 0 & 92 \\
\hline Supplier capability & 8 & 42 & 50 \\
\hline $\begin{array}{l}\text { Sales representative Personal presentation \& } \\
\text { knowledge of the product }\end{array}$ & 8 & 50 & 42 \\
\hline $\begin{array}{l}\text { The need to conform to organizational policies or } \\
\text { government laws e.g., NHIF/ Insurance } \\
\text { requirements }\end{array}$ & & & \\
\hline
\end{tabular}

Furthermore, the study investigated the stages in the buying decision that were considered when making the decision to procure CMLE. Table 5 shows that all respondents (100 percent) indicated that recognition of a problem or need is considered every time while 83 percent indicated that search for and qualification of potential suppliers is considered every time.

Other phases considered every time included evaluation of proposals and selection of supplier (83 percent), determination of specification and quantity of needed item (75 percent), selection of an order routine (66 percent) and acquisition and analysis of proposals (59 percent). However, performance feedback and evaluation (50 percent) was not conducted mostly every time. These findings imply that the county referral hospitals mostly adhered to the stages in the buying decision making process except the performance feedback and evaluation which was occasionally considered. 
Table 5: The stages in the buying decision

\begin{tabular}{|l|l|l|l|}
\hline Phase & $\begin{array}{l}\text { Never } \\
(\boldsymbol{\%})\end{array}$ & $\begin{array}{l}\text { Occasionally } \\
(\boldsymbol{\%})\end{array}$ & $\begin{array}{l}\text { Always } \\
(\boldsymbol{\%})\end{array}$ \\
\hline Recognition of a problem (need) & 0 & 0 & 100 \\
\hline $\begin{array}{l}\text { Determination of specification and quantity of } \\
\text { needed item }\end{array}$ & 8 & 17 & 75 \\
\hline $\begin{array}{l}\text { Search for and qualification of potential } \\
\text { sources/Suppliers }\end{array}$ & 0 & 17 & 83 \\
\hline Acquisition and analysis of proposals & 8 & 33 & 59 \\
\hline Evaluation of proposals and selection of supplier(s) & 0 & 17 & 83 \\
\hline Selection of an order routine & 17 & 17 & 66 \\
\hline Performance feedback and evaluation & 8 & 42 & 50 \\
\hline
\end{tabular}

These findings partly agree with Jefkins (1988) standard model of consumer purchase decision-making process, which includes recognition of needs and wants, information search, evaluation of choices, purchase, and post-purchase evaluation. However, post purchase evaluation was found wanting in the county referral hospitals.

\section{Limitations of the Study}

This study encountered several limitations, which presented challenges in data collection and analysis. First, the availability of the medical superintendents, medical laboratory technologists and procurement officers was very limited, which prolonged the time planned for data collection. Several visits had to be made to get the target participants and to remind them of the need to respond to the questionnaires. However, even with the many reminders through phone calls, emails, and personal visits, six of the ones who had been administered with the questionnaires did not provide their responses. Some participants who did not respond might have provided more information and insight into the study area. Secondly, the study relied on the information provided by the study respondents and hence was determined by their recall capacity and truthfulness. Although participants were informed of the need to provide objective and non-biased information, the research findings still run a risk of relying on some biased and erroneous information. There are also various ethical aspects that needed to be adhered to in the course of the study. Ethical approval for the study was obtained from the medical superintendents of the county hospitals prior to conducting the study. The purpose of the study was explained, and it was made clear that participation in the study was voluntary and that the identity of the respondents would remain confidential. Consent involves three elements: capacity, information, and voluntariness (Saunders et al., 2012). 


\section{Conclusion and Implications}

Hospital staff with responsibility to research on capital medical laboratory equipment when making procurement decisions in public hospitals in Kenya were chief medical laboratory technologists and procurement officers. Hospital staff involved in making procurement decisions for capital medical laboratory equipment were procurement officers and chief medical laboratory technologists. Resources used while researching for the procurement of CMLE included medical or sales representatives, medical literature / catalogues, and referrals from colleagues. Other resources utilized included conferences, seminars, exhibitions, and electronic sources (internet search). Factors considered important when making the decision to procure CMLE included quality, continuity of reagents supply, supplier capability, after sales service, cost of the equipment consumables and ease of use. Other important factors include spare parts availability, brand of the equipment and purchase price of the equipment. The County referral hospitals mostly adhered to the stages in the buying decision making process except on the performance feedback and evaluation which was occasionally considered.

There are at least three broad implications derived from the conclusion of the study. First, public hospitals in Kenya should adopt participatory purchasing models where more stakeholders such as buyers, lower-level employees in hospital departments (users), physicians, and procurement officers included in the buying decision-making. This would ensure that the hospitals do not rely only on top management employees in making such critical decisions. This is expected to increase quality of purchases and thus increasing healthcare delivery. Second, in doing research on capital laboratory medical equipment during the procurement process, the members responsible for researching are encouraged to utilise electronic sources of information more. This is because these sources are efficient and cost effective. They also provide deeper information and can be used to countercheck the information provided by sales or other supplier representatives. Third, the study recommends that in the process of procuring capital laboratory medical equipment, the participants in the procurement process should not overlook the performance feedback and evaluation phase. This is because this phase is critical in informing how well the purchased equipment is performing. This can provide lessons which can be used to improve purchasing systems in the future. 


\section{References}

Babbie, E. (2011) The Practice of Social Research. 13 ${ }^{\text {th }}$ ed. Belmont: Wadsworth Thomson. Bachkirov, A. (2019), Towards a better understanding of organizational buying behavior across cultures: empirical evidence from the Arabian Gulf, Journal of Business \& Industrial Marketing, 34(7), pp. 1521-1532. https://doi.org/10.1108/JBIM-12-2017$\underline{0323}$

Bahadori, M. S. (2012) 'Priority of Determinants Influencing the Behavior of purchasing the Capital Medical Equipment using AHP Model', World Journal of Medical Sciences, 3, pp. 1-6.

Bahadori, M., Sadeghifar, J., Ravangard, R., Salimi, M. and Mehrabian, F. (2012) 'Priority of Determinants Influencing the Behavior of Purchasing the Capital Medical Equipment using AHP Model', World Journal of Medical Sciences, 7(3), pp. 131-136.

Ban, H. (2013) Mixed Research Methods. Greenville USA.

Bastholm, S. M., \& Munksgaard, K. B. (2020). Purchasing's tasks at the interface between internal and external networks. Journal of Business and Industrial Marketing, 35(1), 159-171. https://doi.org/10.1108/JBIM-12-2018-0393

Chikweche, T (2015) Independent Retail and Grocery Shops in Zimbabwe: Survival and Demise in a Crisis and Post-Crisis Era, Journal of Marketing Channels, 22 (2), 121130.

Coolican, H. (2014) Research methods and statistics in psychology. 5th ed. London.

Creswell, J. (2013) Research Design; Qualitative and Quantitative and Mixed Methods Approaches. 3rd ed. London: Sage.

Creswell, J. W. and Creswell, J. D. (2018) Research Design: Qualitative, Quantitative, and Mixed Methods Approaches. 5th edition. Thousand Oaks: Sage.

Dadzie, K. Q., Winston, E., \& Hinson, R. (2015) Competing with Marketing Channels and Logistics in Africa's Booming Markets: An investigation of Emerging Supply Chain Practices in Ghana, Journal of Marketing Channels, 22 (2), 137-152.

Diba, H., Vella, J. and Abratt, R. (2019), Social media influence on the B2B buying process, Journal of Business \& Industrial Marketing, 34(7), pp. 1482-1496. https://doi.org/10.1108/JBIM-12-2018-0403

Dorris, A. (2013) Participatory Approaches to Purchasing Decisions within the Healthcare System. Honors Scholar Thesis, University of Connecticut. 
Gachie, J., 2013. https://softkenya.com/directory/hospitals-in-kenya-clinics-health-centreshealth-facilities-in-kenya/. [Online] Soft Kenya Available at: https://softkenya.com [Accessed 23 March 2018].

Gaoa, M. J. (2003) 'Reducing buyer decision-making uncertainty in organizational purchasing', Journal of Business Research, 58, pp. 397-405.

Gillham, B. (2013) Developing a Questionnaire. 4th Ed. London: Continuum International Publishing Group Ltd.

Google (2013) "The doctor will see you now: How hospital administrators make purchase decisions." Think With Google, October, https://www.thinkwithgoogle.com/intl/en$\mathrm{gb} /$ future-of-marketing/machine-learning/how-hospital-administrators-makepurchase-decisions/

Horne, D. R., Nickerson, D., \& DeFanti, M. (2015) Improving Supply Chain Efficiency Through Electronic Payments: The Case of Micro-Entrepreneurs in Kenya and Tanzania, Journal of Marketing Channels, 22(2), 83-92, https://doi.org/10.1080/1046669X.2015.1018074

Horvath, R. (2013) 'From Evidence to Best Practice in Laboratory Medicine', The Clinical Biochemist Review, 34(2), pp. 47-60.

Juhas, C. (CME Corp, 29 July 2015) 5 Attributes Of Capital Equipment, https://blog.cmecorp.com/5-attributes-of-capital-equipment

Kirankumar P., \& Chauhan, J. D. (2017) 'Six sigma in clinical biochemistry: It matters, measure it', International Journal of Clinical Biochemistry and Research, 4(3), 27074.

Lichtenberger, S., Neal, E. and Ungerman, D. (2010) 'How sourcing excellence can lower hospital costs', Health International, 2010(10), pp. 19 - 29.

Madichie, N.O. and Nyakang'o, M. (2016), An exploratory insight into the workplace demographic challenges in the public sector: A Kenyan perspective, Employee Relations, 38(6), pp. 859-885. https://doi.org/10.1108/ER-01-2015-0002

Monari, D. G. (2017). Influence of Performance Management Initiatives on Service Delivery in State Corporations in Kenya (Doctoral dissertation).

Muema, T. (2019). Effect of Decentralization Frameworks on Service Delivery in Devolved Governments of Kenya. GRIN Verlag.

Muken, R., and Cherny, M. (2013) 'RCM and SM 101: Saving hospitals...one dollar at a time', Healthcare Services \& Technology, pp. 1-53. 
Mwencha, P. M., \& Muathe, S. M. (2019). A principal component analysis of customers' perceived risks for online retailing services: Evidence from Kenya. Journal of Customer Behaviour, 18(3), 167-214.

Ondigi, S. K. and Muturi, W. (2015) 'Factors affecting public procurement of hospital supplies in public health institutions in Kenya: A case study of Kisii Teaching and Referral Hospital, Kenya', International Journal of Economics, Commerce and Management, 3(11), pp. $863-872$.

Piabuo, S. M., and Tieguhong, J. C. (2017) 'Health expenditure and economic growth - a review of the literature and an analysis between the economic community for central African states (CEMAC) and selected African countries', Health Economic review, 7 (23). Doi: 10.1186/s13561-017-0159-1.

Ramadhani, K. (2015) 'Factors affecting implementation of public procurement procedures and practices in Elgeyo-Marakwet County', International Academic Journal of Procurement and Supply Chain Management, 1(5), pp. 121-35.

Republic of Kenya. (2017) Health sector working group report. Nairobi: Ministry of Health.

Robson, C. (2012) Real world research: A resource for social scientists and practitionerresearchers. 6th ed. Oxford: Blackwell.

Saunders, M., Lewis, P. \& Thornhill, A. (2012) Research methods for business students. 6th ed. Harlow: Pearson Education.

Terio, H. (2010) Procurement of medical equipment in Sweden. Stockholm: Karolinska University.

Tseisa, P. A. (2016). Performance management in the Ministry of Health in Lesotho (Doctoral dissertation).

Verhage, R., van de Gronden, J., Awanyo, K., \& Boateng, S. (2002). Procurement reform in the Ghana health sector. Journal of Public Procurement, 2(2), 261-268.

Wagner, K. (2017) '5 Ways to reduce the cost of purchased services', Healthcare Financial Management, 72(7), 36-43.

WHO (2011) Health Technology Assessment of Medical Devices. WHO Medical Device Technical Series, Geneva: World Health Organization.

William, M. and Pride, F. (2009) Foundations of Marketing. 3rd ed. Boston: Houghton Mifflin. 